16. Сукачев В.Н. Руководство к исследованию типов лесов // Госиздат с.-х. и колхозн-кооперат. лит. М.-Л., 1931.

17. Грибова С.А., Исаченко Т.И. Картирование растительности в съемочных масштабах // Полевая геоботаника. IV. 1972. C. 95-136.
18. Нешатаев Ю.Н. Методика обработки геоботанических описаний в учебной практике кафедры геоботаники Ленинградского университета // Методы выделения растительных ассоциаций. Л.: Издательство «Наука» Лениградское отделение, 1971. С. 23-37.

\title{
SUCCESSION AND FEATURES DISTRIBUTION PLANT ASSOCIATIONS IN ROW OF RAILWAYS
}

(C) 2016

N.A. Nikitin, postgraduate student of Biology, Ecology and Methods of Teaching Department

V.V. Solovieva, doctor of biological sciences, professor of Biology, Ecology and Methods of Teaching Department Samara State University of Social Sciences and Education, Samara (Russia)

Abstract. ROW is a specific man-made landscape, in which the processes of change occur in its direction and intensity. Erosion processes, in particular the processes of water erosion of soil, lead not only to changes in the soil, but the plant through changes in soil fertility, nutrient richness, and by changing moisture exchange, structure and texture of soils. The main characteristics of flora undergo structural, quantitative and other changes. Vegetation characteristics, composition of plant associations, the speed and direction of succession, from the initial stage of overgrown weeds and ruderal vegetation to sustainable tree and shrub communities also modify. An ecological and geomorphological zoning shows the prevalence of the most eroded soils in the vicinity of the web. The regularity according to which in most habitats anthropogenic disturbed grow motley-grass-wheatgrass association with a reduction of anthropogenic load becomes dominant forb meadow-grass association. The role of indication of Eletrygia repens L. was also identified as an indicator of habitat disturbance.

Keywords: ROW railways; ecological and geomorphological zoning; soil erosion; succession of plant associations; Eletrygia repens L.; plant associations; anthropogenic transformation of vegetation; vegetation; ruderal vegetation; weeds; phytoindicator.

УДК 581.55:502.72(477.60)

\section{СИНФИТОСОЗОЛОГИЧЕСКАЯ ОЦЕНКА РАСТИТЕЛЬНОСТИ ПАСТБИЩНЫХ ЭКОСИСТЕМ ЮГО-ВОСТОКА УКРАИНЫ} (C) 2016

В.М. Остапко, доктор биологических наук, профессор,

заведующий отделом природной флоры и заповедного дела, заместитель директора по научной работе Донеикий ботанический сад, Донеик (Донеикая Народная Республика)

О.М. Шевчук, доктор биологических наук, заведующий лабораторией ароматических и лекарственных растений Никитский ботанический сад - Национальный научный центр РАН, Ялта, п.г.т. Никита (Россия)

С.А. Приходько, кандидат биологических наук, заведующий отделом фитоэкологии, директор Донеикий ботанический сад, Донеик (Донеикая Народная Республика)

Аннотация. В составе растительности пастбищных степных экосистем юго-востока Украины выявлено 62 раритетные формации (79\% общего их количества) с 338 (52\%) раритетными ассоциациями доминантной классификации. В Зелёную книгу Украины включены 18 формаций с 79 ассоциациями (соответственно - 54\% и $67 \%$ этих синтаксонов растительности региона), остальные формации и ассоциации являются регионально редкими. Приводится перечень раритетных формаций и входящих в них ассоциаций растительности с распределением по типам пастбищных степных экосистем. Самым высоким синтаксономическим разнообразием характеризуются овражно-балочные степные экосистемы, сформировавшиеся на смытых чернозёмах, подстилаемых лёссами (750 ассоциаций из 81 формации), наименьшим - растительность надпойменно-террасовых степей на песках (140 ассоциаций из 24 формаций). Наибольшее количество регионально редких ассоциаций ценотически приуроченны к меловым обнажениям: здесь отмечено 49 ассоциаций из 16 формаций. Большое количество ассоциаций являются стенотопными. Полученные результаты позволяют говорить о высокой синфитосозологической ценности растительности пастбищных экосистем на юго-востоке Украины, что очень важно для сохранения биоразнообразия степного биома. Это следует учитывать при обосновании объектов территориальной охраны биоты, а также - при разработке режимов охраны и расчёте пастбищных нагрузок для конкретных участков.

Ключевые слова: синфитосозология; раритетная формация; раритетная ассоциация; степная экосистема; пастбищная экосистема; юго-восток Украины; Зелёная книга; растительность; синтаксономическое разнообразие; фитоценотическое разнообразие; водораздельная экосистема; овражно-балочная экосистема; надпойменно-террасовая экосистема. 
Постановка проблемы в общем виде и ее связь с важными научными и практическими задачами. Данное сообщение является продолжением осуществляемых авторами исследований растительности природных экосистем юго-востока Украины [1-12], в частности - пастбищных [13-18]. Оценка их фитосозологической значимости важна для оптимального решения вопросов соотношения пасторальной нагрузки и природоохранных мероприятий, позволяющего эксплуатировать эти экосистемы в рамках концепции неистощительного использования природных ресурсов.

Анализ последних исследований и публикаций, в которых рассматривались аспекты этой проблемы и на которых обосновывается автор; выделение неразрешенных раньше частей общей проблемы. Вопросы необходимости охраны растительных сообществ на юго-востоке Украины (Донецкая и Луганская области) впервые были подняты Е.Н. Кондратюком и Р.И. Бурдой, выделившими эталонные, редкие и исчезающие фитоценозы [19]. Наиболее полно проблемы синфитосозологии в регионе рассмотрены В.М. Остапко $[3 ; 20 ; 21]$. К настоящему времени обоснован перечень растительных сообществ региона, нуждающихся в особой охране на государственном и региональном уровнях [22; 23]. Однако полный перечень ассоциаций, отмеченных на юго-востоке Украины, относящихся к раритетной фракции растительности, не опубликован, хотя работа над подготовкой Зелёной книги Донбасса уже несколько лет ведётся [24].

Формирование иелей статьи (постановка задания). Целью данной работы является синфитосозологическая оценка растительности степных пастбищных экосистем на юго-востоке Украины. Объект исследований - раритетные формации и ассоциации растительности следующих степных пастбищных экосистем: водораздельных на развитых чернозёмах, овражно-балочных на смытых чернозёмах, овражнобалочных на смытых чернозёмах на гранитах, овражно-балочных на смытых чернозёмах на известняках, надпойменно-террасовых на мелах, надпойменнотеррасовых на песках [17].

Исследования растительности пастбищных экосистем проводили в период с 1998 г. по 2011 г. маршрутным методом с подробным (полустационарным) изучением флор-изолят [25] с учетом всего разнообразия растительного покрова в их пределах. Обследования проведены почти во всех ботанико-географических хорионах низшего уровня в пределах всей территории региона. Геоботанические исследования проводили методами закладки трансект и пробных площадей, материалы исследований документированы гербарными сборами, анкетами установленного образца, полевыми дневниками.

Полустационарные исследования проводили на участках, прилегающих к территориям Украинского степного природного заповедника (отделения «Хомутовская степь», «Каменные Могилы», «Меловая флора», «Кальмиусское»), Луганского природного заповедника (отделения «Стрельцовская степь», «Станично-Луганское», «Провальская степь»), Национального природного парка «Святые Горы», ботанических заказников «Балка Водяная», «Урочище Плоское», «Сухая балка», «Гектова балка», «Марьина Гора», «Лес на граните» [26].
Изложение основного материала исследования с полным обоснованием полученных научных результатов. Всего в растительности юго-востока Украины отмечено 78 раритетных формаций и 649 ассоциаций [22; 23]. Среди них 33 формации и 11 ассоциаций включены в Зеленую книгу Украины [27].

Растительность пастбищных экосистем юго-востока Украины представлена 1029 ассоциациями в составе 178 формаций, что составляет $37 \%$ ассоциаций и $33 \%$ формаций естественной растительности региона. Для степных экосистем отмечено 920 (33\%) ассоциаций из 147 формаций (27\%) формаций. Наибольшим синтаксономическим разнообразием характеризуются овражно-балочные степные экосистемы, сформировавшиеся на смытых чернозёмах, подстилаемых лёссами (750 ассоциаций из 81 формации), наименьшим - растительность надпойменно-террасовых степей на песках (140 ассоциаций из 24 формаций).

Полный перечень раритетных формаций и входящих в них ассоциаций растительности пастбищных степных экосистем, а также их представленность в каждом типе экосистем приведены в таблице 1 .

Таблица 1 - Представленность раритетных формаций и ассоциаций в степных пастбищных экосистемах юго-востока Украины

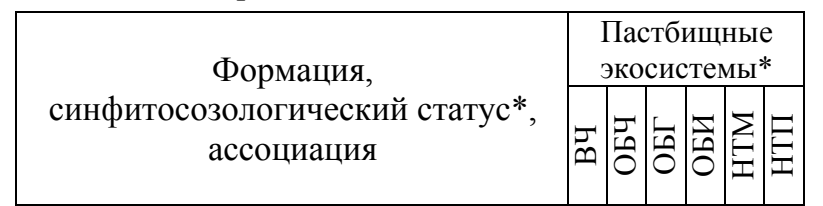

Achilleeta leptophyllae, R:

Achilleetum (leptophyllae) erodiosum

(beketowii)

Agropyreta pectinati, R:

Agropyretum (pectinati) stiposum

(ucrainicae)

Amygdaleta nanae, $\mathrm{U}$ :

Amygdaletum (nanae) bromopsiosum

(inermis)

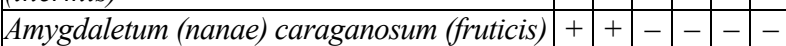

Amygdaletum (nanae) caraganosum

(scythicae)

Amygdaletum (nanae) crinitariosum (villosae)

Amygdaletum (nanae) elytrigiosum

(stipifoliae)

Amygdaletum (nanae) elytrigiosum

(trichophorae)

Amygdaletum (nanae) festucosum (rupicolae)

Amygdaletum (nanae) festucosum (valesiacae)

Amygdaletum (nanae) galiosum (ruthenicae)

Amygdaletum (nanae) inulosum (germanicae)

Amygdaletum (nanae) linosum (czerniaevii)

Amygdaletum (nanae) marrubiosum

(praecocis)

Amygdaletum (nanae) poosum (angustifoliae) +

Amygdaletum (nanae) securigerosum (variae) +

Amygdaletum (nanae) stiposum (capillatae)

Amygdaletum (nanae) talictrosum (mini)

Amygdaletum (nanae) teucriosum (polii)

Amygdaletum (nanae) thymosum (dimorphi)

Caraganeto (fruticis) - Amygdaletum

(nanae) rososum (subpygmaeae)

Caraganeto (fruticis) - Amygdaletum

(nanae) stiposum (lessingianae)

Caraganeto (fruticis) - Amygdaletum

(nanae) festucosum (valesiacae) 
Остапко В.М., Шевчук О.М., Приходько С.А.

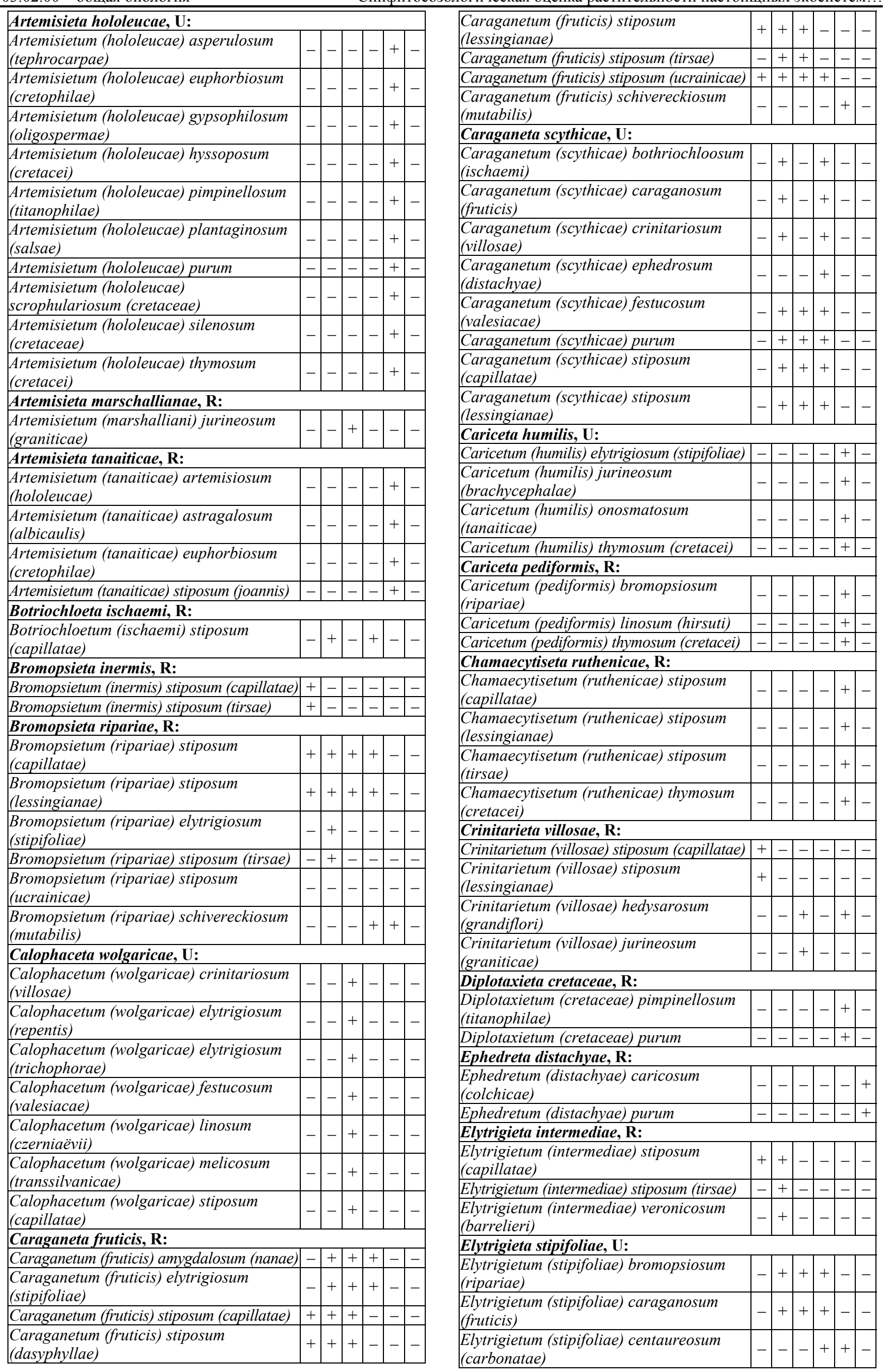


Остапко В.М., Шевчук О.М., Приходько С.А.

Синфитосозологическая оценка растительности пастбищных экосистем.

03.02 .00 - общая биология

Elytrigietum (stipifoliae) festucosum (valesiacae)

Elytrigietum (stipifoliae) koeleriosum (cristata)

Elytrigietum (stipifoliae) plantaginosum (lanceolatae)

Elytrigietum (stipifoliae) securigerosum

(variae)

Elytrigietum (stipifoliae) purum

Elytrigietum (stipifoliae) stiposum (capil

(capillatae)

Elytrigietum (stipifoliae) stiposum

(lessingianae)

Elytrigieta trichophorae, R:

Elytrigietum (trichophorae) stiposum

(capillatae)

Erodieta beketowii, U:

Erodietum (beketowii) dianthosum

(pseudoarmeriae)

Erodietum (beketowii) festucosum

(valesiacae)

Erodietum (beketowii) jurineosum

(graniticae)

Erodietum (beketowii) pimpinellosum

(titanophilae)

Erodietum (beketowii) purum

Erodietum (beketowii) stiposum (capillatae)

Erodietum (beketowii) thymosum (granitici)

Erodietum (beketowii) thymosum

(kaljmijussici)

Euphorbieta cretophilae, $\mathbf{R}$ :

Euphorbietum (cretophilae) artemisiosum

(tanaiticae)

Euphorbietum (cretophilae) jurineosum

(brachycephalae)

Euphorbietum (cretophilae) thymosum

(calcarei)

Euphorbietum (cretophilae)

helianthemosum (cretophili)

Euphorbietum (cretophilae) thymosum

(cretacei)

\section{Festuceta beckeri, R:}

Festucetum (beckeri) stiposum

(borysthenicae)

Festucetum (beckeri) stiposum (grafianae)

Festucetum (beckeri) stiposum (lessingianae)

Festucetum (beckeri) veronicosum (incanae)

Festuceta cretaceae, R:

Festucetum (cretaceae) elytrigiosum

(repentis)

Festucetum (cretaceae) purum

Festucetum (cretaceae) salviosum (nutantis)

Festucetum (cretaceae) thymosum (cretacei)

Festuceta rupicolae, R:

\begin{tabular}{|l|l|l|l|l|l|l|}
\hline Festucetum (rupicolae) stiposum (ucrainicae) & + & + & - & - & - & - \\
\hline
\end{tabular}

Festuceta valesiacae, R:

Festucetum (valesiacae) onosmatosum

(tanaiticae)

Festucetum (valesiacae) stiposum (capillatae)

Festucetum (valesiacae) stiposum

(dazyphyllae)

Festucetum (valesiacae) stiposum

(lessingianae)

Festucetum (valesiacae) stiposum (tirsae)

Festucetum (valesiacae) stiposum

(ucrainicae)

Festucetum (valesiacae) veronicosum

(incanae)
Filipenduleta vulgaris, R:

Filipenduletum (vulgaris) stiposum

(capillatae)

Genisteta scythicae, U:

Genistetum (scythicae) bromopsiosum

(ripariae)

Genistetum (scythicae) bromopsiosum

(ripariae)

Genistetum (scythicae) centaureosum

(marschallianae)

Genistetum (scythicae) cephalariosum

(uralensis)

Genistetum (scythicae) pimpinellosum

(titanophilae)

Genistetum (scythicae) purum

Genistetum (scythicae) stiposum (asperellae)

Genistetum (scythicae) thymosum (calcarei)

Genistetum (scythicae) thymosum (dimorphi)

Hedysareta cretacei, $\mathrm{U}$ :

Hedysaretum (cretacei) artemisiosum

(hololeucae)

Hedysaretum (cretacei) artemisiosum

(tanaiticae)

Hedysaretum (cretacei) festucosum

(cretaceae)

Hedysaretum (cretacei) genistosum

(tanaiticae)

Helianthemeta cretophili, R:

Helianthemetum (cretophili) caricosum

(praecocis)

Helianthemetum (cretophili) euphorbiosum

(cretophili)

Helianthemetum (cretophili) jurineosum

(brachycephalae)

Helianthemetum (cretophili) onosmatosum

(tanaiticae)

Helianthemetum (cretophili) purum

Helianthemetum (cretophili) thymosum

(cretacei)

Hyssopeta cretaceae, $\mathrm{U}$ :

Hyssopetum (cretacei) artemisiosum

(hololeucae)

Hyssopetum (cretacei) artemisiosum

(nutantis)

Hyssopetum (cretacei) artemisiosum

(tanaiticae)

Hyssopetum (cretacei) asperulosum

(tephrocarpae)

Hyssopetum (cretacei) cephalariosum

(uralensis)

Hyssopetum (cretacei) euphorbiosum

(cretophilae)

Hyssopetum (cretacei) genistosum

(tanaiticae)

Hyssopetum (cretacei) gypsophilosum

(oligospermae)

Hyssopetum (cretacei) pimpinellosum

(titanophilae)

Hyssopetum (cretacei) plantaginosum

(salsae)

Hyssopetum (cretacei) purum

Hyssopetum (cretacei) scrophullariosum

(cretaceae)

Hyssopetum (cretacei) thymosum (cretacei)

Jurineeta brachycephalae, R:

Jurineetum (brachycephalae) caraganosum

(scyticae)

Jurineetum (brachycephalae)

helianthemosum (cretophili)

Koelerieta cristatae, R:

\begin{tabular}{|l|l|l|l|l|l|l|}
\hline Koelerietum (cristatae) stiposum (ucrainicae) & + & - & - & + & - & - \\
\hline
\end{tabular} 
Остапко В.М., Шевчук О.М., Приходько С.А.

\section{Lineta czerniaëvii, R:}

\begin{tabular}{|l|l|l|l|l|l|l|}
\hline Linetum (czerniaëvii) amygdalosum (nanae) & - & + & - & + & - & - \\
\hline
\end{tabular}

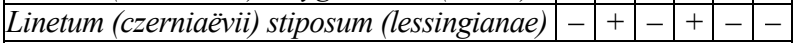

Matthioleta fragrantis, R:

Matthioletum (fragrantis) purum

Onosmateta tanaitici, $\mathrm{R}$ :

Onosmatetum (tanaitici) artemisium

(hololeucae)

Onosmatetum (tanaitici) hedysarosum

(grandiflori)

Onosmatetum (tanaitici) helianthemosum

(cretophili)

Onosmatetum (tanaitici) koeleriosum

(cristatae)

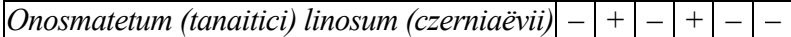

Onosmatetum (tanaitici) purum

Onosmatetum (tanaitici) scrophulariosum

(cretaceae)

Onosmatetum (tanaitici) thymosum (calcarei)

Onosmatetum (tanaitici) thymosum (cretacei)

Paeonieta tenuifoliae, R:

Paeonietum (tenuifoliae) elytrigiosum

(repentis)

Paeonietum (tenuifoliae) festucosum

(valesiacae)

Paeonietum (tenuifoliae) filipendulosum

(vulgaris)

Paeonietum (tenuifoliae) fragariosum

(viridis)

Paeonietum (tenuifoliae) poosum

(angustifoliae)

Pimpinelleta titanophilae, R:

Pimpinelletum (titanophilae) euphorbiosum (cretophilae)

Pimpinelletum (titanophilae) festucosum

(cretaceae)

Pimpinelletum (titanophilae) hyssoposum

(cretacei)

\section{Poeta angustifoliae, R:}

Poetum (angustifoliae) elytrigiosum

(stipifoliae)

Poetum (angustifoliae) stiposum (capillatae)

Poetum (angustifoliae) stiposum

(lessingianae)

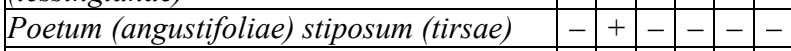

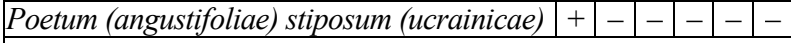

Roseta subpygmaeae, $\mathrm{R}$ :

Rosetum (subpygmaeae) caraganosum

(fruticis)

Rosetum (subpygmaeae) festucosum

(valesiacae)

Rosetum (subpygmaeae) stiposum (capillatae)

Rosetum (subpygmaeae) purum

Salvieta nutantis, R:

\begin{tabular}{|l|l|l|l|l|l|l|}
\hline Salvietum (nutantis) linosum (czerniaëvii) & - & + & - & - & - & - \\
\hline Salvietum (nutanis) thymosum (granitici) & - & - & + & - & - & - \\
\hline
\end{tabular}

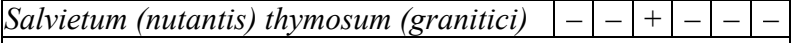

Scrophularieta cretaceae, $\mathrm{R}$ :

Scrophularietum (cretaceae) artemisiosum (hololeucae)

Scrophularietum (cretaceae) asperulosum

(tephrocarpae)

Scrophularietum (cretaceae) hyssoposum

(cretacei)

Scrophularietum (cretaceae)

pimpinellosum (titanophilae)

Scrophularietum (cretaceae) thymosum

(cretacei)

Scrophularieta donetzicae, R:

Scrophularietum (donetzicae) thymosum

(granitici)

\section{Stipeta capillatae, $\mathrm{U}$ :}

Stipetum (capillatae) artemisiosum

(marschallianae)

Stipetum (capillatae) agrimoniosum

(eupatoriae)

\begin{tabular}{|l|l|l|l|l|l}
\hline Stipetum (capillatae) artemisiosum (repentis) & + & + & + & + & + \\
\hline
\end{tabular}

Stipetum (capillatae) bothriochloosum

(ischaemi)

Stipetum (capillatae) bromopsiosum

(ripariae)

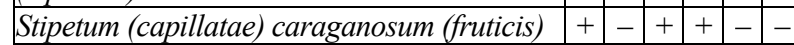

Stipetum (capillatae) caraganosum

(scythicae)

Stipetum (capillatae) caricosum (supinae)

Stipetum (capillatae) cephalariosum

(uralensis)

Stipetum (capillatae) crinitariosum (villosae)

Stipetum (capillatae) elytrigiosum

(intermediae)

Stipetum (capillatae) elytrigiosum

(maeoticae)

Stipetum (capillatae) elytrigiosum (repentis)

Stipetum (capillatae) elytrigiosum (stipifoliae)

Stipetum (capillatae) elytrigiosum

(trichophorae)

Stipetum (capillatae) euphorbiosum

(seguieranae)

Stipetum (capillatae) festucosum (beckeri)

Stipetum (capillatae) festucosum (rupicolae)

Stipetum (capillatae) festucosum (valesiacae)

Stipetum (capillatae) filipendulosum

(vulgaris)

Stipetum (capillatae) fragariosum (viridis)

Stipetum (capillatae) galiosum (ruthenicae)

Stipetum (capillatae) inulosum (hirtae)

Stipetum (capillatae) jurineosum

(brachycephalae)

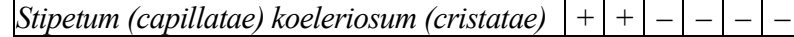

Stipetum (capillatae) limoniosum (platyphylli) +

Stipetum (capillatae) linosum (czerniaëvii)

Stipetum (capillatae) medicaginosum

(romanicae)

Stipetum (capillatae) phleosum (phleoidis)

Stipetum (capillatae) pimpinellosum

(titanophilae)

Stipetum (capillatae) phlomoidosum

(tuberosae)

Stipetum (capillatae) plantaginosum

(lanceolatae)

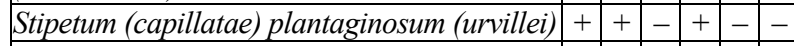

Stipetum (capillatae) poosum (angustifoliae) $+++_{+}++_{+}+-$

\begin{tabular}{ll|l|l|l|l|l|}
\hline Stipetum (capillatae) poosum (compressae) & + & + & - & - & + & + \\
\hline
\end{tabular}

Stipetum (capillatae) potentillosum

(arenariae)

Stipetum (capillatae) purum

Stipetum (capillatae) salviosum (nutantis)

Stipetum (capillatae) salviosum (tesquicolae)

Stipetum (capillatae) securigerosum (variae)

Stipetum (capillatae) stiposum (dasyphillae)

Stipetum (capillatae) stiposum (lessingianae)

Stipetum (capillatae) stiposum (ucrainicae)

Stipetum (capillatae) teucriosum (polii)

Stipetum (capillatae) thalictrosum (mini)

Stipetum (capillatae) thymosum (calcarei)

Stipetum (capillatae) thymosum (cretacei)

Stipetum (capillatae) thymosum (dimorphi)

Stipetum (capillatae) thymosum (granitici)

Stipetum (capillatae) thymosum

(marschalliani) 
Остапко В.М., Шевчук О.М., Приходько С.А.

Синфитосозологическая оценка растительности пастбищных экосистем.

03.02 .00 - общая биология

Stipetum (capillatae) thymosum

(pseudogranitici)

Stipetum (capillatae) veronicosum

(maeoticae)

Stipeta borysthenicae, U:

Stipetum (borysthenicae) artemisiosum

(repentis)

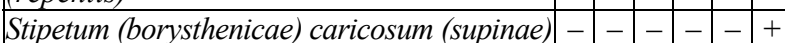

Stipetum (borysthenicae) centaureosum

(carbonatae)

\begin{tabular}{ll|l|l|l|l|l|}
\hline Stipetum (borysthenicae) festucosum (beckeri) & - & - & - & - & - & + \\
\hline
\end{tabular}

Stipetum (borysthenicae) festucosum

(valesiacae)

Stipetum (borysthenicae) helichrysosum

(arenarii)

Stipetum (borysthenicae) koeleriosum

(sabuletori)

Stipetum (borysthenicae) potentillosum

(arenariae)

Stipetum (borysthenicae) pulsatillosum

(latifoliae)

Stipetum (borysthenicae) pulsatillosum

(ucrainicae)

Stipetum (borysthenicae) stiposum (zalesskii)

Stipetum (borysthenicae) stiposum

(ucrainicae)

Stipeta dazyphyllae, $\mathrm{U}$

Stipetum (dazyphyllae) artemisiosum (marschallianae)

Stipetum (dazyphyllae) bromopsiosum

(ripariae)

Stipetum (dazyphyllae) caraganosum

(fruticis)

Stipetum (dazyphyllae) elytrigiosum

(intermediae)

Stipetum (dazyphyllae) elytrigiosum

(stipifoliae)

Stipetum (dazyphyllae) festucosum

(rupicolae)

Stipetum (dazyphyllae) festucosum

(valesiacae)

Stipetum (dazyphyllae) filipendulosum

(vulgaris)

Stipetum (dazyphyllae) poosum

(angustifoliae)

Stipetum (dazyphyllae) salviosum (nutantis)

Stipetum (dazyphyllae) stiposum (capillatae)

Stipetum (dazyphyllae) stiposum

(lessingianae)

Stipetum (dazyphyllae) stiposum (tirsae)

Stipetum (dazyphyllae) stiposum (ucrainicae)

Stipeta grafianae, R:

Stipetum (grafianae) amygdalosum (nanae)

Stipetum (grafianae) artemisiosum

(marschallianae)

Stipetum (grafianae) bromopsiosum (inermis)

Stipetum (grafianae) caraganosum (fruticis)

Stipetum (grafianae) caricosum (praecocis)

Stipetum (grafianae) elytrigiosum

(intermediae)

Stipetum (grafianae) elytrigiosum (repentis)

Stipetum (grafianae) elytrigiosum (stipifoliae)

Stipetum (grafianae) elytrigiosum

(trichophorae)

Stipetum (grafianae) festucosum (rupicolae)

Stipetum (grafianae) festucosum (valesiacae)

Stipetum (grafianae) inulosum (germanicae)

Stipetum (grafianae) jurineosum

(arachnoideae)

Stipetum (grafianae) kochiosum (prostratae)

Stipetum (grafianae) koeleriosum (cristatae)
Stipetum (grafianae) medicaginosum

(romanicae)

Stipetum (grafianae) poosum (angustifoliae)

Stipetum (grafianae) poosum (bulbosae)

Stipetum (grafianae) stiposum (capillatae)

Stipetum (grafianae) stiposum (ucrainicae)

Stipeta graniticolae, U:

Stipetum (graniticolae) festucosum

(valesiacae)

Stipetum (graniticolae) poosum (bulbosae)

Stipetum (graniticolae) stiposum (capillatae)

Stipetum (graniticolae) stiposum

(dazyphyllae)

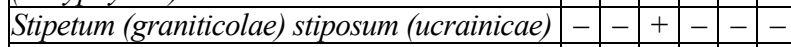

Stipetum (graniticolae) thym

\section{Stipeta joannis, R:}

Stipetum (joannis) anthericosum (ramosi)

Stipetum (joannis) elytrigiosum (cretaceae)

Stipetum (joannis) festucosum (valesiacae)

Stipetum (joannis) koeleriosum (cristatae)

Stipetum (joannis) onosmatosum (tanaiticae)

Stipeta lessingianae, U:

Stipetum (lessingianae) agropyrosum

(pectinatae)

Stipetum (lessingianae) artemisiosum

(repentis)

Stipetum (lessingianae) artemisiosum

(tanaiticae)

Stipetum (lessingianae) bromopsiosum

(ripariae)

Stipetum (lessingianae) caraganosum

(fruticis)

Stipetum (lessingianae) caraganosum

(scythicae)

Stipetum (lessingianae) centaureosum

(carbonatae)

Stipetum (lessingianae) centaureosum

(marschallianae)

Stipetum (lessingianae) centaureosum

(ruthenicae)

Stipetum (lessingianae) crambosum

(tataricae)

Stipetum (lessingianae) crinitaroisum

(villosae)

Stipetum (lessingianae) elytrigiosum

(intermediae)

Stipetum (lessingianae) elytrigiosum

(repentis)

Stipetum (lessingianae) elytrigiosum

(stipifoliae)

Stipetum (lessingianae) elytrigiosum

(trichophorae)

Stipetum (lessingianae) ephedrosum

(distachyae)

Stipetum (lessingianae) festucosum

(rupicolae)

Stipetum (lessingianae) festucosum

(valesiacae)

Stipetum (lessingianae) filipendulosum

(vulgaris)

Stipetum (lessingianae) hedysarosum

(grandiflori)

Stipetum (lessingianae) jurineosum

(arachnoideae)

Stipetum (lessingianae) koeleriosum

(cristatae)

Stipetum (lessingianae) linosum (czerniaevii)

Stipetum (lessingianae) medicaginosum

(romanicae)

Stipetum (lessingianae) nepetosum

(parviflorae)

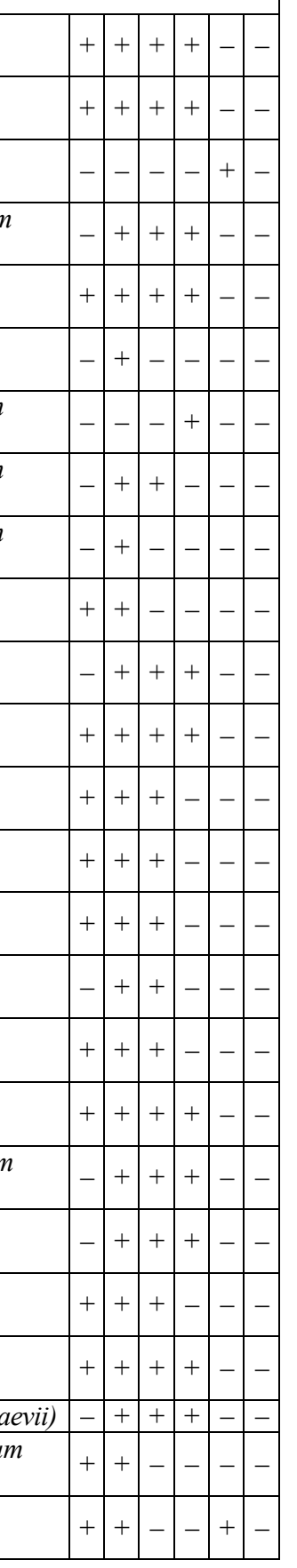

Самарский научный вестник. 2016. № 4 (17) 
Остапко В.М., Шевчук О.М., Приходько С.А.

Stipetum (lessingianae) onosmatosum (tanaiticae)

Stipetum (lessingianae) paeoniosum

(tenuifoliae)

Stipetum (lessingianae) pimpinellosum

(titanophilae)

Stipetum (lessingianae) poosum

(angustifoliae)

Stipetum (lessingianae) purum

Stipetum (lessingianae) salviosum (nutantis)

Stipetum (lessingianae) stiposum

(dazyphyllae)

Stipetum (lessingianae) stiposum (grafianae)

Stipetum (lessingianae) stiposum (ucrainicae)

Stipetum (lessingianae) teucriosum (polii)

Stipetum (lessingianae) thymosum (dimorphi)

Stipetum (lessingianae) thymosum (granitici)

Stipetum (lessingianae) thymosum

(marschalliani)

Stipeta tirsae, U:

Stipetum (tirsae) achilleosum (stepposae)

Stipetum (tirsae) bromopsiosum (inermis)

Stipetum (tirsae) bromopsiosum (ripariae)

Stipetum (tirsae) caraganosum (fruticis)

Stipetum (tirsae) caricosum (praecocis)

Stipetum (tirsae) caricosum (supinae)

Stipetum (tirsae) centaureosum (ruthenici)

Stipetum (tirsae) centaureosum

(trichocephalae)

Stipetum (tirsae) crinitariosum (villosae)

Stipetum (tirsae) elytrigiosum (intermediae)

Stipetum (tirsae) elytrigiosum (stipifoliae)

Stipetum (tirsae) festucosum (rupicolae)

Stipetum (tirsae) festucosum (valesiacae)

Stipetum (tirsae) purum

Stipetum (tirsae) hierochloosum (repentis)

Stipetum (tirsae) inulosum (hirtae)

Stipetum (tirsae) stiposum (capillatae)

Stipetum (tirsae) stiposum (dazyphyllae)

Stipetum (tirsae) stiposum (grafianae)

Stipetum (tirsae) stiposum (lessingianae)

Stipetum (tirsae) stiposum (ucrainicae)

Stipetum (tirsae) thymosum (marshalliani)

Stipeta ucrainicae, $\mathrm{U}$ :

\begin{tabular}{|l|l|l|l|l|l|l|}
\hline Stipetum (ucrainicae) artemisiosum (repentis) & - & + & - & - & - & - \\
\hline Stipetum (ucrainicae) bromopsiosum & & & & & & \\
\hline
\end{tabular}

Stipetum (ucrainicae) bromopsiosum

(ripariae)

\begin{tabular}{l|l|lll|lll}
\hline Stipetum (ucrainicae) caraganosum (fruticis) & + & + & - & - & - & - \\
\hline
\end{tabular}

Stipetum (ucrainicae) crinitariosum (villosae) +

Stipetum (ucrainicae) elytrigiosum

(intermediae)

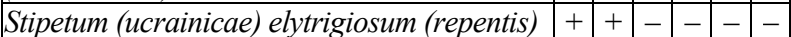

Stipetum (ucrainicae) euphorbiosum

(seguieranae)

Stipetum (ucrainicae) euphorbiosum

(stepposae)

Stipetum (ucrainicae) festucosum (rupicolae)

Stipetum (ucrainicae) festucosum (valesiacae)

Stipetum (ucrainicae) koeleriosum (cristatae)

Stipetum (ucrainicae) poosum (angustifoliae)

Stipetum (ucrainicae) poosum (bulbosae)

Stipetum (ucrainicae) purum

Stipetum (ucrainicae) salviosum (nutantis)

Stipetum (ucrainicae) stiposum (capillatae)

Stipetum (ucrainicae) stiposum (dazyphyllae)

Stipetum (ucrainicae) stiposum (lessingianae)

Stipetum (ucrainicae) stiposum (tirsae)

Stipetum (ucrainicae) tanacetosum (millefolii)

Stipetum (ucrainicae) teucriosum (polii)
Stipetum (ucrainicae) thymosum (dimorphi)

Stipetum (ucrainicae) thymosum

(marschalliani)

Stipetum (ucrainicae) veronicosum (spuriae)

Stipeta zaleskii, U:

Stipetum (zalesskii) bromopsiosum (ripariae)

Stipetum (zalesskii) caraganosum (fruticis)

Stipetum (zalesskii) centaureosum

(carbonatae)

Stipetum (zalesskii) centaureosum

(ruthenicae)

Stipetum (zalesskii) elytrigiosum (repentis)

Stipetum (zalesskii) festucosum (valesiacae)

Stipetum (zalesskii) helichrysosum

(arenariae)

Stipetum (zalesskii) filipendulosum (vulgaris)

Stipetum (zalesskii) poosum (angustifoliae)

Stipetum (zalesskii) pulsatillosum (latifoliae)

Stipetum (zalesskii) securigerosum (variae)

Stipetum (zalesskii) stiposum (capillatae)

Stipetum (zalesskii) stiposum (grafianae)

Stipetum (zalesskii) stiposum (lessingianae)

Stipetum (zalesskii) stiposum (tirsae)

Teucrieta polii, R:

Teucrietum (polii) stiposum (capillatae)

Teucrietum (polii) thymosum (cretacei)

\section{Thymeta cretacei, R:}

Thymetum (cretacei) artemisiosum

(hololeucae)

Thymetum (cretacei) caricosum (humilis)

Thymetum (cretacei) erucastrosum (cretacei)

Thymetum (cretacei) euphorbiosum

(cretophilae)

Thymetum (cretacei) helianthemosum

(cretophili)

Thymetum (cretacei) hyssoposum (cretacei)

Thymetum (cretacei) onosmatosum

(tanaiticae)

Thymetum (cretacei) scrophulariosum

(cretaceae)

Thymetum (cretacei) thymosum (didukhii)

Thymeta didukhii, R:

\begin{tabular}{|l|l|l|l|l|l|l|}
\hline Thymetum (didukhii) thymosum (kondratjukii) & - & - & - & - & + & - \\
\hline
\end{tabular}

Thymeta dimorphi, R:

\begin{tabular}{|l|l|l|l|l|l|l|}
\hline Thymetum (dimorphi) stiposum (lessingianae) & - & + & + & + & - & - \\
\hline Thymetum (dimorphi) helianthemosum & & & & & \\
\hline
\end{tabular}

Thymetum (dimorphi) helianthemosum

(cretophili)

Thymeta granitici, $\mathbf{R}$ :

Thymetum (granitici) erodiosum (beketowii)

Thymetum (granitici) thymosum

(kaljmijussici)

Thymeta kondratjukii, R:

Thymetum (kondratjukii) festucosum

(valesiacae)

Thymetum (kondratjukii) linosum

(ucrainicae)

Thymetum (kondratjukii) purum

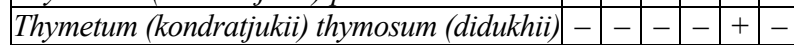

\section{Thymeta marschalliani, R:}

Thymetum (marschalliani) stiposum

(lessingianae)

Thymeta pseudogranitici, R:

Thymetum (pseudogranitici) erodiosum (beketowii)

Thymetum (pseudogranitici) festucosum

(valesiacae)

Thymetum (pseudogranitici) jurineosum

(graniticae)

Thymetum (pseudogranitici) purum 
*Примечание: U - растительные сообщества, включённые в Зелёную книгу Украины [27]; R - растительные сообщества, редкие на региональном уровне [3; 22]; пастбищные степные экосистемы: ВЧ водораздельные на развитых чернозёмах, ОБЧ овражно-балочные на смытых чернозёмах, ОБГ овражно-балочные на смытых чернозёмах на гранитах, ОБИ - овражно-балочные на смытых чернозёмах на известняках, НТМ - надпойменно-террасовые на мелах, НТП - надпойменно-террасовые на песках

Всего для степных экосистем отмечено 62 раритетные формации и 338 раритетных ассоциаций, что составляет $79 \%$ раритетных формаций и $52 \%$ общего количества раритетных ассоциаций растительности региона (табл. 2).

Таблица 2 - Показатели синфитосозологического разнообразия степных пастбищных экосистем юговостока Украины

\begin{tabular}{|c|c|c|c|c|c|c|}
\hline \multirow{2}{*}{$\begin{array}{c}\text { Показатели } \\
\text { синтаксономического } \\
\text { разнообразия }\end{array}$} & \multicolumn{6}{|c|}{$\begin{array}{l}\text { Пастбищные } \\
\text { экосистемы* }\end{array}$} \\
\hline & $F_{n}$ & $\begin{array}{l}\overrightarrow{5} \\
0\end{array}$ & 官 & $\stackrel{\nabla}{0}$ & $\underset{\Xi}{\sum}$ & $\Xi$ \\
\hline Количество формаций & 20 & 24 & 23 & 21 & 28 & 6 \\
\hline $\begin{array}{l}\text { \% общего количества } \\
\text { формаций в регионе }\end{array}$ & 26 & 31 & 30 & 27 & 36 & 8 \\
\hline Количество ассоциаций & 151 & 209 & 136 & 119 & 119 & 35 \\
\hline \begin{tabular}{|l} 
\% общего количества \\
ассоциацй в регионе
\end{tabular} & 23 & 32 & 21 & 18 & 19 & 5 \\
\hline $\begin{array}{l}\text { Включено в Зеленую книгу } \\
\text { Украины формаций }\end{array}$ & 15 & 17 & 19 & 15 & 16 & 3 \\
\hline $\begin{array}{l}\text { \% общего количества вклю- } \\
\text { ченных в Зеленую книгу } \\
\text { Украины формаций }\end{array}$ & 45 & 52 & 58 & 45 & 47 & 9 \\
\hline $\begin{array}{l}\text { Включено в Зеленую книгу } \\
\text { Украины ассоциаций }\end{array}$ & 114 & 173 & 106 & 90 & 47 & 6 \\
\hline $\begin{array}{l}\text { \% общего количества вклю- } \\
\text { ченных в Зеленую книгу } \\
\text { Украины ассоциаций }\end{array}$ & 23 & 35 & 22 & 18 & 9 & 1 \\
\hline $\begin{array}{l}\text { Количество регионально } \\
\text { редких формаций }\end{array}$ & 14 & 16 & 13 & 12 & 16 & 3 \\
\hline $\begin{array}{l}\text { \% общего количества регио- } \\
\text { нально редких формаций }\end{array}$ & 31 & 36 & 29 & 27 & 36 & 7 \\
\hline $\begin{array}{l}\text { Количество регионально } \\
\text { редких ассоциаций }\end{array}$ & 44 & 34 & 29 & 29 & 44 & 8 \\
\hline $\begin{array}{l}\text { \% общего количества регио- } \\
\text { нально редких ассоциаций }\end{array}$ & 29 & 22 & 19 & 19 & 29 & 5 \\
\hline
\end{tabular}

*Примечание: пастбищные степные экосистемы: ВЧ - водораздельные на развитых чернозёмах, ОБЧ овражно-балочные на смытых чернозёмах, ОБГ овражно-балочные на смытых чернозёмах на гранитах, ОБИ - овражно-балочные на смытых чернозёмах на известняках, НТМ - надпойменно-террасовые на мелах, НТП - надпойменно-террасовые на песках

Из них18 формаций и 79 ассоциаций включены в Зеленую книгу Украины (что составляет 54\% и 67\% соответственно таких формаций и ассоциаций в растительности региона); остальные являются регионально редкими [3].

Для водораздельных степей на развитых чернозёмах отмечено 20 раритетных формаций со 151 ассо- циацией, из которых 8 формаций и 130 ассоциаций включены в Зелёную книгу Украины [27], а 12 формаций и 21 ассоциация являются регионально редкими. Для овражно-балочных степей на гранитах указывается 209 ассоциаций из 24 формаций, из которыхх 166 ассоциаций из 9 формаций включены в Зелёную книгу Украины, а 43 ассоциации из 15 формаций являются регионально редкими.

Несколько меньше представлены раритетные ассоциации и формации в растительности овражнобалочных степей на смытых чернозёмах, подстилаемых известняками и надпойменно-террасовых - на мелах. Здесь отмечено всего 136 ассоциаций из 23 формаций, из которых 119 ассоциаций из 21 формации - регионально редкие.

Наибольшее количество раритетных ассоциаций и формаций отмечено в овражно-балочных степях на смытых чернозёмах: 209 ассоциаций из 24 формаций, наименьшее - в песчаных степях: 53 ассоциации из 9 формаций.

Среди формаций, включённых в Зелёную книгу Украины, только в овражно-балочных степях на смытых чернозёмах на гранитах представлены Calophaceta wolgaricae с 6 ассоциациями, Erodieta beketowii с 7 ассоциациями и Stipeta graniticolae с 6 ассоциациями. Только в надпойменно-террасовых степях на смытых чернозёмах на мелах встречаются Cariceta humilis с 4 ассоциациями, Hedysareta cretacei c 4 ассоциациями, Helianthemeta cretophili с 6 ассоциациями, Hyssopeta cretacei с 13 ассоциациями и Artemisieta hololeucae с 10 ассоциациями. Формация Stipeta borysthenicae c 13 ассоциациями представлена исключительно в растительности надпойменно-террасовых степей на песках.

Наибольшее количество регионально редких ассоциаций ценотически приурочены к меловым обнажениям: здесь отмечено 49 ассоциаций из 16 формаций. Из них 8 формаций характерны только для растительности этого варианта степей: Cariceta pediformis c 3 ассоциациями, Chamaecytiseta ruthenicae с 4 ассоциациями, Diplotaxieta cretaceae с 3 ассоциациями, Festuceta cretaceae с 4 ассоциациями, Artemisieta tanaiticae с 4 ассоциациями, Matthioleta fragrantis c ассоциацией Matthioletum (fragrantis) purum, Thymeta cretacei с 9 ассоциациями, Thymeta didukhii с ассоциацией Thymetum (didukhii) thymosum (kondratjukii) и Thymeta kondratjukii с 4 ассоциациями.

Среди регионально редких формаций и ассоциаций, которые ценотически приурочены к определенному типу местообитаний, отметим четыре формации, которые представлены только в степных фитоценозах на гранитах: Thymeta granitici с 2 ассоциациями, Thymeta pseudogranitici с 4 ассоциациями, Scrophularieta donetzicae с ассоциацией Scrophularietum (donetzicae) thymosum (granitici), Achilleeta leptophyllae c ассоциацией Achilleetum (leptophyllae) erodiosum (beketowii) и Artemisieta marschallianae с ассоциацией Artemisietum (marschallianae) jurineosum (graniticae); и формация, которая представлена только на песках - Ephedreta distachyae с 2 ассоциациями.

Выводы исследования и перспективы дальнейших изысканий данного направления. В составе растительности пастбищных степных экосистем юго-востока Украины выявлено 62 раритетные формации (79\% 
Остапко В.М., Шевчук О.М., Приходько С.А.

общего их количества) с 338 (52\%) раритетными ассоциациями доминантной классификации. В Зелёную книгу Украины включены 18 формаций с 79 ассоциациями (соответственно - 54\% и 67\% этих синтаксонов растительности региона), остальные формации и ассоциации являются регионально редкими. Большое количество ассоциаций являются стенотопными. Полученные результаты позволяют говорить о высокой синфитосозологической ценности растительности пастбищных экосистем на юго-востоке Украины, что очень важно для сохранения биоразнообразия степного биома. Это следует учитывать при обосновании объектов территориальной охраны биоты, а также при разработке режимов охраны и расчёте пастбищных нагрузок для конкретных участков.

\section{СПИСОК ЛИТЕРАТУРЫ:}

1. Приходько С.А. Адаптация флоры басейну Казенного Торця до антропогенного впливу: автореф. дис. ... канд. биол. наук. Киев, 1994. 20 с.

2. Остапко В.М. Продромус естественной растительности юго-востока Украины. Донецк, 1995. 142 с.

3. Остапко В.М. Эйдологические, популяционные и ценотические основы фитосозологии на юговостоке Украины. Донецк: «Лебедь», 2005. 408 с.

4. Остапко В.М., Купрюшина Л.В. Фитоценотическое разнообразие кустарниковых степей на юговостоке Украины и его созологическая оценка // Промислова ботаніка: стан та перспективи розвитку: матеріали VI міжнар. наук. конф. «Промислова ботаніка: стан та перспективи розвитку» (Донецьк, 4-7 жовтня 2010 р.). Донецьк, 2010. С. 346-349.

5. Глухов А.3., Остапко В.М., Приходько С.А. Фиторазнообразие регионального ландшафтного парка «Меотида» // Ландшафты, растительный покров и животный мир регионального ландшафтного парка «Меотида»: монография / Г.Н. Молодан, С.А. Приходько, С.В. Третьяков и др. Донецк: Изд-во «Ноулидж», 2010. С. 15-78.

6. Купрюшина Л.В., Остапко В.М. Фітоценорізноманіття чагарникових степів на південному сході України та його моделювання в штучних фітоценозах // материалы Международной научной конференции «Современная биология растений», посвящённой 65летию основания ЮНЕСКО, 340-летию становления анатомии растений и 145-летию выхода работы основоположника генетики Г. Менделя «Опыты над растительными гибридами», 100-летию основания гербария Луганского НАУ (Луганск, 20-24 июня 2011 г.) // Ред. И.Д. Соколов. Луганск: Элтон-2, 2011. С. 32-34.

7. Остапко В.М., Сова Т.В., Назаренко А.С., Ибатулина Ю.В. Флора и растительность отделения «Трехизбенская степь» Луганского природного заповедника // Промышленная ботаника. 2012. Вып. 12. C. 67-74.

8. Коломійчук В.П., Остапко В.М., Яровий С.С. ПЗ Український степовий // Фіторізноманіття заповідників і національних природних парків України. Ч. 1. Біосферні заповідники. Природні заповідники / Колектив авторів під ред. В.А. Онищенка і Т.Л. Андрієнко. Київ: Фітосоціоцентр, 2012. С. 336-378.

9. Коломійчук В.П., Остапко В.М. Національний природний парк «Меотида» // Фіторізноманіття заповідників і національних природних парків України. Ч. 2. Національні природні парки / Колектив авторів під ред. В.А. Онищенка і Т.Л. Андрієнко. Київ: Фітосоціоцентр, 2012. С. 312-329.

10. Остапко В.М., Шпилева Н.В., Дьякова О.В. НПП Святі гори // Фіторізноманіття заповідників і національних природних парків України. Ч. 2. Національні природні парки / Колектив авторів під ред. В.А. Онищенка і Т.Л. Андрієнко. Київ: Фітосоціоцентр, 2012. С. 423-440.

11. Остапко В.М., Приходько С.А. Бородавка В.О. Фітоценотичне різноманіття природних лісів Донеччини // Ліси Донеччини: науково-інформаційний довідник. Луцьк: Ініціал, 2015. С. 140-147.

12. Lisetskii F.N., Tokhtar V.K., Ostapko V.M., Prykhodko S.A., Petrunova T.V. Regularities and Features of Differentiation and Anthropogenic Transformation of Steppe Vegetation // Terrestrial Biomes: Geographic Distribution, Biodiversity and Environmental Threats / eds.: M. Nguyen. Hauppauge, NY, 2016. Chap. 4. P. 103-126.

13. Остапко В.М., Шевчук О.М. Флора та рослинність лучних пасовищ південного сходу України // Вісник Львівського університету. Серія біологічна. 2004. Вип. 36. С. 57-62.

14. Шевчук О.М., Остапко В.М. Сукцесії рослинного покриву в пасовищних екосистемах південного сходу України // Матеріали міжнародної наукової конференції, присвяченої 50-річчю функціонування високогірного біологічного стаціонару «Пожижевська». Львів: 2008. С. 443-444.

15. Шевчук О.М. Роль пасовищних екосистем в збереженні біорізноманітності // Промышленная ботаника. 2012. Вип.12 С. 61-66.

16. Шевчук О.М. Флористична диференціація пасовищних екосистем як основа їх збереження та вітворення: автрореф. дис. ... д-ра біол. наук. Київ, 2013. $40 \mathrm{c}$.

17. Остапко В.М., Шевчук О.М., Приходько С.А. К вопросу классификации экосистем юго-востока Украины // Самарский научный вестник. 2016. № 1 (14). C. 41-47.

18. Остапко В.M., Шевчук О.М., Приходько С.А. Синтаксономическое разнообразие растительности пастбищных экосистем юго-востока Украины // Самарский научный вестник. 2016. № 3 (16). С. 40-45.

19. Бурда P.І., Кондратюк С.М. Матеріали до охорони еталонних, рідкісних і зникаючих фітоценозів у Донбасі // Інтродукція та акліматизація рослин на Україні. 1983. Вип. 23. С. 5-9.

20. Остапко В.М. Ценотична різноманітність фітобіоти на південному сході України та іiі охорона // Укр. ботан. журн. 1999. Т. 56, № 5. С. 536-543.

21. Остапко В.М. Созологическая оценка и охрана естественного растительного покрова Донецкого Приазовья // Мережа ключових ботанічних територій у Приазовському регіоні: матеріали міжнародної наради (6-7 жовтня 2011 р., м. Мелітополь). Київ: Альтерпрес, 2011. С. 27-30.

22. Приходько С.А., Остапко В.М., Купрюшина Л.В. Синтаксономічна різноманітність рослинності Південного Сходу України в аспекті синфітосозології // Промышленная ботаника. 2012. Вып. 12.С. 53-60.

23. Остапко В.М., Приходько С.А. Раритетні на південному сході України рослинні угруповання, не включені до Зеленої книги України // Матеріали IV Міжнародної наукової конференції «Сучасна біологія 
рослин», присвяченої 260-річчю виходу праці К. Ростов-на-Дону: Издательство Южного Федерального Ліннея «Species plantarum», 115-річчю відкриття подівійного запліднення С.Г. Навашиним і 60-річчю створення моделі структури ДНК Д. Уотсоном і Ф. Криком (Україна, Луганськ, 03-07 червня 2013 р.) // Ред. І.Д. Соколов. Луганськ: Елтон-2, 2013. С. 16-18.

24. Остапко В.М., Приходько С.А. Фиторазнообразие юго-востока Украины и перспективы его сохранения // Роль ботанических садов в сохранении и мониторинге биоразнообразия: сборник материалов / отв. ред. Т.В. Вардуни, П.А. Дмитриев, О.А. Капралова.

университета, 2015. С. 243-246.

25. Бурда Р.И. Антропогенная трансформация флоры. Киев: Наук. думка, 1991. 168 с.

26. Донбас заповідний. Науково-інформаційний довідник-атлас / Під заг. ред. С.С. Куруленка, С.В. Третьякова. Донецьк: ДФ ДІПКПК Мінекоресурсів України, 2003. 160 с.

27. Зелена книга України / Під. ред. чл.-кор. Я.П. Дідуха. К.: Альтпрес, 2009. 448 с.

\title{
SYNPHYTOSOZOLOGICAL ASSESSMENT OF PASTURE ECOSYSTEMS VEGETATION IN SOUTH-EAST UKRAINE
}

(C) 2016

V.M. Ostapko, doctor of biological sciences, professor,

head of Natural Flora and Nature Conservation Department, deputy director for scientific work Donetsk Botanical Garden, Donetsk (Donetsk People's Republic)

O.M. Shevchuk, doctor of biological sciences, head of Aromatic and Medicinal Plants Laboratory

Nikita Botanical Garden - National Research Center of Russian Academy of Sciences, Yalta, u.t.s. Nikita (Russia)

S.A. Prikhodko, candidate of biological sciences,

head of Phytoecology Department, director

Donetsk Botanical Garden, Donetsk (Donetsk People's Republic)

Abstract. As part of the pasture vegetation of steppe ecosystems of the south-east of Ukraine we found 62 rarity formations (79\% of the total number), with $338(52 \%)$ rarity associations of dominant classification. Green Book of Ukraine includes 18 formations with 79 associations (respectively, 54\% and 67\% of these syntaxa of regional vegetation), and the rest of the formations and associations are rare for this region. Rare vegetation formations and their associations are listed and distributed by types of grassland steppe ecosystems. The highest syntaxonomic variety is characteristic for gully and ravine steppe ecosystems formed on eroded chernozems underlain by loess ( 750 associations of 81 formations), the least syntaxonomic diversity is found in above-floodplain terraced steppes on the sands (140 associations of 24 formations). The greatest number of regionally rare associations is cenotically confined to the chalk outcrops (49 associations of 16 formations). A large number of associations are stenotopic. These results suggest a high synphytosozological value of pasture ecosystems vegetation in the south-east of Ukraine, which is very important for the conservation of the steppe biome biodiversity. It should be taken into account when grounding establishment of the local reserves for biota protection, their protection regimes and performing pasture load calculations for specific areas.

Keywords: synphytosozology; rare formation; rare association; steppe ecosystem; grassland ecosystem; south-east of Ukraine; Green Book; vegetation; syntaxonomic variety; phytocenotic diversity; watershed ecosystem; ravine-gully ecosystem; above-flood plain terraced ecosystem.

УДК 598.2

\section{ВЛИЯНИЕ СОВРЕМЕННЫХ ПРЕОБРАЗОВАНИЙ ИНФРАСТРУКТУРЫ ГОРОДА САМАРЫ НА БИОЛОГИЮ ГНЕЗДОВАНИЯ ЯСТРЕБА-ПЕРЕПЕЛЯТНИКА} (C) 2016

\author{
И.С. Павлов, кандидат биологических наук, заместитель председателя \\ Самарское отделение Союза охраны птии России, Самара (Россия) \\ В.Н. Макаренков, преподаватель \\ Детская художественная школа № 2, Самара (Россия)
}

\begin{abstract}
Аннотация. На основании наблюдений с 1997 г. за соколообразными птицами, обитающими на территории города Самары, было выявлено, что наиболее многочисленным и широко распространенным пернатым хищником в данных условиях оказался ястреб-перепелятник. За этот период численность данного вида в указанном районе росла. В настоящее время она оценивается нами более чем в 50 пар. В условиях города большинство ястребов населяют типичные для них стации - лесные массивы, с большой долей молодых деревьев, как естественные, так и посадки, с площадью от 1 га. При этом в последние 5-7 лет наметилась тенденция к гнездованию ястребов в нетипичных для них очень малых по площади насаждениях в густонаселенных районах города. В 2016 г. нами было обнаружено гнездо перепелятников на пустыре практически в географическом центре Самары площадью не более 0,5 га, в 50 м от дороги и буквально в 5 м от тропы. При этом ястребам удалось успешно вырастить выводок - из гнезда вылетело 3 слетка (2 самки и 1 самец). Таким образом, несмотря на активное окультуривание и освоение лесопарковых зон и пустырей в городе Самара, осуществляемых в последние годы, перепелятники, находя здесь, в первую очередь, оптимальные кормовые условия, проявляют практически весь адаптационный потенциал для приспособления к меняющимся условиям.
\end{abstract}

